\title{
Efeitos de níveis nutricionais de energia sobre o desempenho e a qualidade de ovos de codornas européias na fase inicial de postura
}

\author{
Sergio Luiz de Toledo Barreto', Bárbara Josefina de Sousa Quirino ${ }^{2}$, Claudson Oliveira Brito², \\ Regina Tie Umigi ${ }^{2}$, Marcelle Santana de Araujo², Tatiana Cristina da Rocha ${ }^{2}$, Claiton Gonçalves \\ Pereira $^{3}$
}

\footnotetext{
1 Departamento de Zootecnia/UFV.

2 Pós-graduação em Zootecnia DZO/UFV.

${ }^{3}$ Graduação em Medicina Veterinária.
}

RESUMO - Objetivou-se avaliar os efeitos de diferentes níveis de EM sobre o desempenho e a qualidade de ovos de codornas européias em postura. Foram utilizadas 240 codornas européias dos 56 aos 168 dias de idade, distribuídas em um delineamento inteiramente casualizado, com cinco tratamentos $(2.650,2.750,2.850,2.950$ e $3.050 \mathrm{kcal} \mathrm{de} \mathrm{EM} / \mathrm{kg}$ ), seis repetições e oito aves por unidade experimental. As rações foram formuladas à base de milho e farelo de soja e continham $20 \% \mathrm{~PB}, 2,5 \% \mathrm{Ca}$, $1,17 \%$ lisina e $0,802 \%$ metionina+cistina total. Foram analisados os consumos de ração (g/ave/dia) e de energia (kcal de EM/ ave/dia), a produção total de ovos (\%/ave/dia) e de ovos comercializáveis (\%/ave/dia), o peso (g) e a massa dos ovos (g/ave/ dia), a conversão alimentar ( $\mathrm{kg}$ de ração/kg de ovo e por dúzia de ovos), o ganho de peso corporal (g), a eficiência energética (kcal de EM/dúzia e por quilo de ovos), os pesos de gema, albúmem e casca (g) e a concentração de colesterol na gema (mg/g). O aumento dos níveis de EM na ração ocasionou redução linear do consumo de ração e dos pesos de ovo, de gema e de albúmem e melhora linear da conversão alimentar (por massa e por dúzia de ovos) e de eficiência da utilização de energia para produção de uma dúzia de ovos. Observou-se comportamento quadrático para a produção de ovos, indicando maior produção em aves alimentadas com ração contendo $2.900 \mathrm{kcal} \mathrm{de} \mathrm{EM} / \mathrm{kg}$. Os demais parâmetros avaliados não foram influenciados pelos níveis de energia. Rações para codornas européias em fase inicial de postura devem conter $3.050 \mathrm{kcal}$ de EM/kg (correspondente a um consumo de $82,4 \mathrm{kcal}$ de EM/ave/dia) para melhor conversão alimentar por massa e por dúzia de ovos ou $2.900 \mathrm{kcal}$ de EM/kg (consumo de $87 \mathrm{kcal}$ de EM/ave/dia) para melhor produção de ovos.

Palavras-chave: Coturnix coturnix coturnix, energia, produção de ovos, qualidade de ovos

\section{Effects of energy nutritional levels on performance and egg quality of European quails in the initial laying phase}

\begin{abstract}
The effects of increasing dietary ME levels on performance and egg quality of 240 laying European quails from 56 to 168 days of age were evaluated in this experiment. The experiment was analyzed as a complete randomized design with five treatments $(2,650,2,750,2,850,2,950$, and $3,050 \mathrm{kcal} \mathrm{ME} / \mathrm{kg})$, six replicates and eight birds per experimental unit. The corn, soybean meal-based diets were formulated to contain $20 \%$ of $\mathrm{CP}, 2.5 \%$ of $\mathrm{Ca}, 1.17 \%$ of lysine and $0.802 \%$ of methionine + cystine. Feed intake (g/bird/day), energy intake (kcal ME/bird/day), total egg production (\%/bird/day), commercial egg production (\%/bird/day), egg weight ( $\mathrm{g}$ ), egg mass (g/bird/day), feed conversion ( $\mathrm{kg} / \mathrm{kg}$ of egg and $\mathrm{kg} / \mathrm{egg}$ dozen), body weight gain (g), energy efficiency utilization (kcal ME/ egg dozen and kcal ME/ egg mass), weights of yolk (g), albumen (g) and shell (g) and yolk cholesterol concentration $(\mathrm{mg} / \mathrm{g}$ ) were analyzed. Increasing dietary ME levels decreased linearly feed intake and weights of egg, yolk and albumen and increased feed conversion (feed:egg mass and feed:egg dozen ratios) and energy efficiency utilization per egg dozen. It was observed quadratic effect on egg production; the birds fed diet with 2,900 ME/kg showed the best production. No treatment effect on the other parameters was observed. It was concluded that diets for European quails in the initial laying phase must contain 3,050 kcal ME/kg (intake of $82.4 \mathrm{kcal} \mathrm{ME/bird/day),} \mathrm{for} \mathrm{better} \mathrm{feed:egg} \mathrm{mass} \mathrm{and}$ feed:egg dozen ratio, or 2,900 kcal ME/kg (intake of $87.1 \mathrm{kcal} \mathrm{ME} / \mathrm{bird} / \mathrm{day}$ ) for better egg production.
\end{abstract}

Key Words: Coturnix coturnix coturnix, egg production, egg quality, energy

\section{Introdução}

Atualmente, três espécies de codornas estão disponíveis para a exploração da coturnicultura industrial: a codorna americana ou a Bobwhite quail (Colinus virginianus), a japonesa (Cotnurnix coturnix japonica) e a européia (Coturnix coturnix coturnix). Essas aves possuem características peculiares que direcionam suas 
aptidões para carne (européia e americana) ou ovos (japonesa).

Entre a espécie e as subespécies mencionadas, a japonesa é a mais difundida mundialmente. Contudo, a criação de codornas européias também tem sido muito difundida no Brasil, principalmente por pequenos e médios produtores, para produção de carne e ovos. Essas aves são maiores que as da subespécie japonesa e chegam (as fêmeas) a pesar de 280 a $300 \mathrm{~g}$ quando adultas, sendo 80 a $100 \%$ mais pesadas, o que resulta em maior consumo de ração (Albino \& Barreto, 2003).

No entanto, Móri et al. (2005a) mencionaram que são poucas as informações sobre o potencial produtivo da linhagem européia quanto ao consumo de ração, à conversão alimentar por dúzia de ovos e à qualidade dos ovos e, portanto, não se conhece sua dupla aptidão.

Considerando que, segundo Oliveira (2003), a espécie européia consome na fase de produção aproximadamente 36 g/dia e que 60 a $70 \%$ dos custos de produção são provenientes da alimentação, a determinação das exigências nutricionais de codornas européias é primordial na sua criação, principalmente quando há escassez de estudos envolvendo esta espécie.

Entre as exigências nutricionais, a de energia dietética é importante, pois é o componente nutricional que regula o consumo e, conseqüentemente, o desempenho das aves. Tanto o excesso quanto a deficiência no consumo de ração ocasionam perda de produtividade. Segundo Neto (1999), o excesso de energia pode promover superovulação, aumento da produção de ovos de duas gemas e da absorção de óvulos na cavidade abdominal, conduzindo a aumento do intervalo de postura e, conseqüentemente, dos prejuízos na produção.

$\mathrm{Na}$ formulação de rações práticas, o consumo de nutrientes é regulado pela energia pré-determinada, estando relacionado ao nível energético da dieta (Belo, 2000). Freitas et al. (2005) observaram que codornas japonesas em postura alimentadas com dietas contendo 2.585 a $2.885 \mathrm{kcal}$ de EM/kg apresentam menor consumo de ração e menor peso de ovos com o aumento do nível energético da ração.

Do mesmo modo, Murakami et al. (1993) avaliaram níveis de 2.500 a $3.100 \mathrm{kcal}$ de EM/kg e Belo (2000) níveis de 2.600 a $3.000 \mathrm{kcal}$ de EM/kg de ração em codornas japonesas e encontraram, respectivamente, redução de 17,3 e 10,8\% no consumo de ração quando fornecido o maior nível de energia.

Em uma vasta revisão de literatura, não foi encontrado nenhum trabalho no qual tenham sido determinadas as exigências de energia para codornas européias na fase de produção; todos os estudos foram relacionados à subespécie japonesa.

Assim, objetivou-se neste trabalho avaliar os efeitos de diferentes níveis de EM na ração sobre o desempenho e a qualidade dos ovos de codornas européias na fase inicial de postura.

\section{Material e Métodos}

O experimento foi realizado no setor de Avicultura do Departamento de Zootecnia da Universidade Federal de Viçosa utilizando-se 400 codornas européias (Coturnix coturnix coturnix), fêmeas, com um dia de idade. As aves foram alojadas e recriadas em piso, onde receberam ração formulada segundo exigências descritas pelo NRC (1994), contendo $24 \%$ de PB e $2.900 \mathrm{kcal}$ de EM/kg até o início da produção de ovos.

Aos 40 dias de idade, as aves foram pesadas individualmente. Duzentas e quarenta aves foram selecionadas segundo a conformação e o peso corporal e, posteriormente, foram distribuídas em delineamento inteiramente casualizado, com cinco tratamentos (níveis de energia), seis repetições e oito aves por unidade experimental. As aves foram alojadas em gaiolas de arame galvanizado, de modo que todas as unidades experimentais apresentassem o mesmo peso médio inicial. As gaiolas (1,0 m de comprimento x 0,23 m de largura x $0,20 \mathrm{~m}$ de altura) foram dispostas em três andares, montadas em esquema de escada.

Cada gaiola foi subdividida em duas repartições iguais de $0,50 \mathrm{~m}$, com capacidade para oito aves, proporcionando uma área de $115 \mathrm{~cm}^{2} /$ ave. Sobre o piso de cimento, logo abaixo das gaiolas, foi disposta uma camada de maravalha para absorção da umidade das excretas. O comedouro foi posicionado na parte frontal e o bebedouro na parte posterior da gaiola, sendo ambos do tipo calha e em chapa galvanizada.

Durante o período pré-experimental (40 a 56 dias de idade), as aves receberam rações contendo $20 \%$ de PB, $2.900 \mathrm{kcal}$ de EM/kg e 2,5\% de Ca, conforme o NRC (1994). Aos 50 dias de idade, as unidades experimentais foram reavaliadas para que todas apresentassem a mesma produção de ovos. O período experimental foi iniciado aos 56 dias de idade, sendo composto de quatro períodos de 28 dias, totalizando 112 dias.

As exigências nutricionais para a fase de produção (56 a 168 dias) utilizadas nas formulações das dietas foram as preconizadas pelo NRC (1994), exceto as de metionina+ cistina e lisina, que foram baseadas nas recomendações de Pinto et al. (2003a,b). 
Para determinação das exigências energéticas, foram formuladas cinco dietas isoprotéicas e isoaminoacídias, à base de milho e farelo de soja, contendo cinco níveis de EM $(2.650,2.750,2.850,2.950$ e $3.050 \mathrm{kcal} \mathrm{de} \mathrm{EM} / \mathrm{kg})$, constituindo os tratamentos experimentais (Tabela 1). Essas rações foram formuladas com base nas composições dos ingredientes descritas por Rostagno et al. (2000).

A água foi disponibilizada à vontade e a ração foi fonecida duas vezes ao dia, às 8 e $16 \mathrm{~h}$. O programa de iluminação teve início por volta do 40 o dia de idade, com fornecimento inicial de 14 horas de luz diária e com aumentos semanais de 30 minutos até atingir 17 horas de luz por dia, programa mantido até o final do período experimental.

Foram analisados os consumos de ração (g/ave/dia) e de energia (kcal de EM/ave/dia), a produção total de ovos (\%/ave/dia) e de ovos comercializáveis (\%/ave/dia), o peso (g) e a massa de ovos (g/ave/dia), a conversão alimentar (kg de ração/kg de ovo e kg de ração/dúzia de ovo), o ganho de peso corporal (g), a eficiência energética (kcal de EM/ dúzia de ovo e kcal de EM/kg de ovo), os pesos médios de gema, de albúmem e de casca (g) e a concentração de colesterol na gema ( $\mathrm{mg} / \mathrm{g})$.

A produção de ovos comercializáveis (PROC) refere-se à porcentagem de ovos viáveis à comercialização, excluindo-se os quebrados, trincados ou anormais (DEF), e foi obtida pela fórmula: $\mathrm{PROC}=100-\mathrm{DEF}$.

Durante os três últimos dias de cada período, foram pesados todos os ovos íntegros produzidos em cada repetição para avaliação do peso médio dos ovos. Para obtenção dos componentes do ovo, foram avaliados os pesos de gema, albúmem e casca utilizando-se quatro ovos de cada repetição, coletados aleatória e diariamente do total de ovos coletados nos três últimos dias de cada período. Os ovos de cada repetição e de cada dia foram pesados individualmente em balança com precisão de $0,01 \mathrm{~g}$ e, após as pesagens, foram identificados e quebrados. A gema de cada ovo foi pesada e a respectiva casca foi lavada e seca ao ar para posterior obtenção do peso da casca. O peso do albúmem foi calculado como a diferença entre o peso do ovo e os pesos de gema e casca.

Tabela 1 - Composição química e valor nutricional das rações para codornas na fase de postura (na matéria natural)

Table 1 - Chemical composition and nutritional values of the diets for laying European quails (as-fed basis)

\begin{tabular}{|c|c|c|c|c|c|}
\hline \multirow[t]{2}{*}{$\begin{array}{l}\text { Ingrediente } \\
\text { Ingredient }\end{array}$} & \multicolumn{5}{|c|}{$\begin{array}{c}\text { Nível de EM, kcal } / \mathrm{kg} \\
\text { ME Level, kcal/kg }\end{array}$} \\
\hline & 2.650 & 2.750 & 2.850 & 2.950 & 3.050 \\
\hline Milho (Corn) & 53,222 & 50,657 & 50,767 & 52,064 & 52,383 \\
\hline Farelo de soja (Soybean meal) & 33,900 & 34,380 & 34,360 & 34,120 & 34,060 \\
\hline Óleo de soja (Soybean oil) & 1,000 & 3,000 & 4,100 & 4,800 & 5,830 \\
\hline Calcário (Limestone) & 5,338 & 5,332 & 5,332 & 5,335 & 5,336 \\
\hline Fosfato bicálcico (Dicalcium phosphate) & 1,314 & 1,320 & 1,319 & 1,316 & 1,316 \\
\hline Sal (Salt) & 0,279 & 0,280 & 0,280 & 0,280 & 0,280 \\
\hline Areia lavada (Washed sand) & 4,450 & 4,540 & 3,350 & 1,590 & 0,300 \\
\hline DL-metionina (DL-methionine 99\%) & 0,176 & 0,179 & 0,179 & 0,178 & 0,177 \\
\hline L-lisina $\mathrm{HCl}$ (L-lysine $\mathrm{HCl}$ ) & 0,121 & 0,112 & 0,113 & 0,117 & 0,118 \\
\hline Cloreto de colina $60 \%$ (Choline chloride $60 \%$ ) & 0,040 & 0,040 & 0,040 & 0,040 & 0,040 \\
\hline Suplemento vitamínico $(\text { Vitamin supplement })^{1}$ & 0,050 & 0,050 & 0,050 & 0,050 & 0,050 \\
\hline Suplemento mineral (Mineral supplement) ${ }^{2}$ & 0,100 & 0,100 & 0,100 & 0,100 & 0,100 \\
\hline Antioxidante (Antioxidant) $^{3}$ & 0,010 & 0,010 & 0,010 & 0,010 & 0,010 \\
\hline \multirow{2}{*}{\multicolumn{6}{|c|}{$\begin{array}{l}\text { Composição calculada } \\
\text { Calculated composition }\end{array}$}} \\
\hline & & & & & \\
\hline $\mathrm{PB}(C P), \%$ & 20,00 & 20,00 & 20,00 & 20,00 & 20,00 \\
\hline $\mathrm{EM}(M E), \mathrm{kcal} / \mathrm{kg}$ & 2.650 & 2.750 & 2.850 & 2.950 & 3.050 \\
\hline $\mathrm{Ca}, \%$ & 2,500 & 2,500 & 2,500 & 2,500 & 2,500 \\
\hline $\mathrm{P}$ total $($ Total P), \% & 0,567 & 0,567 & 0,567 & 0,567 & 0,567 \\
\hline P disponível (Available P), \% & 0,350 & 0,350 & 0,350 & 0,350 & 0,350 \\
\hline $\mathrm{Na}, \%$ & 0,150 & 0,150 & 0,150 & 0,150 & 0,150 \\
\hline Lisina (Lysine), \% & 1,170 & 1,170 & 1,170 & 1,170 & 1,170 \\
\hline Metionina (Methioinine), \% & 0,485 & 0,485 & 0,485 & 0,485 & 0,485 \\
\hline Metionina + Cistina $($ Met + cys $), \%$ & 0,802 & 0,802 & 0,802 & 0,802 & 0,802 \\
\hline Treonina (Threonine), \% & 0,779 & 0,779 & 0,779 & 0,779 & 0,779 \\
\hline Triptofano (Tryptophan), \% & 0,252 & 0,253 & 0,253 & 0,253 & 0,252 \\
\hline
\end{tabular}

1 Níveis de garantia por quilo do produto (guaranty levels per $\mathrm{kg}$ of product): vit. A - 12.000 .000 UI; vit. $\mathrm{D}_{3}-3.600 .000 \mathrm{UI}$; vit. E - $3.500 \mathrm{UI}$; vit. $\mathrm{B}_{1}-2,5 \mathrm{~g}$; vit. $\mathrm{B}_{6}-8,0 \mathrm{~g}$; ac. pantotênico (pantothenic acid) - $12,0 \mathrm{~g}$; biotina (biotine) - 0,20 g; vit. $\mathrm{K}_{3}-3,0 \mathrm{~g}$; ácido fólico (folic acid) - 1,5 g; ácido nicotínico (nicotinic acid) $-40,0 \mathrm{~g}$; vit. $\mathrm{B}_{12}-20.000 \mathrm{mcg}$; Se - 0, $15 \mathrm{~g}$; Veículo q.s.p (inert filler) - $1.000 \mathrm{~g}$.

2 Níveis de garantia por quilo do produto (guaranty level per kg of product): Mn - 16,0 g; Fe - 100,0 g; Zn - 100,0 g; Cu - 20,0 g; Co - 2,0 g; I - 2,0 g; Veículo q.s.p. (inert filler) - $1.000 \mathrm{~g}$.

${ }^{3}$ Butil-hidroxi-tolueno (butylhydroxytoluene). 
O teor de colesterol na gema foi determinado utilizando-se metodologia proposta por Bragagnolo \& Amaya (2003), aplicada por meio do HPLC/RP (Cromatografia Líquida de Alta Performance).

Os parâmetros avaliados foram submetidos à análise de variância a 5\% utilizando-se o programa SAEG - Sistema para Análises Estatísticas e Genéticas (UFV, 2004). Posteriormente, os efeitos dos níveis de energia foram estimados por meio de análise de variáveis pelos modelos de regressão linear e quadrática, conforme o melhor ajustamento obtido para cada variável, considerando o comportamento biológico das aves.

\section{Resultados e Discussão}

Houve efeito significativo $(\mathrm{P}<0,01)$ dos níveis de EM na ração sobre o consumo médio de ração, a produção de ovos, o peso do ovo, a conversão alimentar por dúzia e por massa de ovos (Tabela 2), a eficiência energética por dúzia de ovos e os pesos de gema e de albúmem (Tabela 3). No entanto, os níveis de EM não influenciaram significativamente ( $\mathrm{P}>0,05)$ o consumo diário de EM, a produção de ovos comercializáveis, a massa de ovo (Tabela 2), a eficiência energética por massa de ovos, o ganho de peso das aves, o peso de casca e a concentração de colesterol na gema do ovo (Tabela 3).

Verificou-se redução linear $(\mathrm{P}<0,01)$ diária de 0,01172 g/ave no consumo de ração para cada kcal de aumento no nível de EM/kg de ração ( $\hat{Y}=63,31020$ -
0,011721X; $\left.\mathrm{R}^{2}=0,90\right)$. Sabe-se que o nível energético da dieta constitui fator regulador da ingestão de nutrientes e da EM. Esta quantidade de EM consumida depende ainda das necessidades da ave, do peso corporal, da fase de postura, do crescimento, dos níveis de mantença e do ambiente de criação.

De fato, o consumo diário de energia manteve-se praticamente constante em todos os tratamentos, variando de 82,4 a 87,1 kcal de EM/ave, possivelmente em virtude da redução no consumo com o aumento da energia da ração. Como a variação no consumo de energia foi pequena, este efeito foi não significativo $(\mathrm{P}>0,05)$, apesar da grande amplitude entre o menor e o maior nível de EM avaliado (2.650 e $3.050 \mathrm{kcal} / \mathrm{kg}$, respectivamente), indicando que o consumo por codornas, em relação ao nível de energia da ração, é similar ao de galinhas poedeiras (Begin, 1968). Esses resultados corroboram aqueles verificados por Murakami et al. (1993) e Freitas et al. (2005), que também notaram redução linear do consumo de ração com o aumento do nível de energia de 2.500 para 3.100 kcal e de 2.585 a $2.885 \mathrm{kcal} / \mathrm{kg}$ de ração, respectivamente. O consumo diário de energia observado neste trabalho está de acordo também com o verificado por Freitas et al. (2005), que constataram não haver efeito significativo no consumo diário de energia de codornas japonesas.

Segundo Yamane et al. (1980) e NRC (1994), o consumo diário de energia por codornas japonesas para máxima produção deve ser de 63 a $75 \mathrm{kcal}$. O consumo de energia por codornas européias neste experimento variou de 82,4 a

Tabela 2 - Valores médios de consumo de ração (CR) e de energia metabolizável (CEM), produção total de ovos (PRO) e de ovos comercializáveis (PROC), peso (PO) e massa de ovo (MO) e conversão alimentar por massa de ovo (CAMO) e por dúzia de ovos (CADZ) de codornas européias alimentadas com rações com diferentes níveis de EM

Table 2 - Average values of feed intake (FI), ME intake (MEI), total egg production (EP), commercial egg production (CEP), egg weight (EW), egg mass (EM), feed:egg mass ratio (FCEM) and feed: egg dozen ratio (FCDZ) of European quails according to the dietary ME levels

\begin{tabular}{|c|c|c|c|c|c|c|}
\hline \multirow{2}{*}{$\begin{array}{l}\text { Variável } \\
\text { Variable }\end{array}$} & \multicolumn{5}{|c|}{$\begin{array}{c}\text { Nível de EM (kcal/kg) } \\
\text { ME level }\end{array}$} & \multirow[t]{2}{*}{$\mathrm{CV}(\%)$} \\
\hline & 2.650 & 2.750 & 2.850 & 2.950 & 3.050 & \\
\hline $\mathrm{CR}(\mathrm{g})^{1}(F I)$ & 31,9 & 31,0 & 30,8 & 29,5 & 27,0 & 7,436 \\
\hline $\mathrm{CEM}(\mathrm{kcal} / \mathrm{kg})(M E I)$ & 84,6 & 86,2 & 87,1 & 86,9 & 82,4 & 7,621 \\
\hline PRO $(\%)^{2}(E P)$ & 85,4 & 91,3 & 94,1 & 91,4 & 91,0 & 6,012 \\
\hline $\operatorname{PROC}(\%)(C E P)$ & 99,5 & 99,0 & 97,1 & 99,9 & 99,4 & 3,197 \\
\hline PO $(\mathrm{g})^{3}(E W)$ & 12,72 & 12,67 & 12,30 & 12,20 & 12,00 & 3,235 \\
\hline MO (g/ave/dia) (EM, g/bird/day) & 10,76 & 11,55 & 11,56 & 11,14 & 10,97 & 7,246 \\
\hline CAMO $(\mathrm{kg} / \mathrm{kg})^{4} \quad($ FECM $)$ & 2,977 & 2,719 & 2,686 & 2,656 & 2,532 & 7,468 \\
\hline CADZ $(\mathrm{kg} / \text { dúzia })^{5}(F C D Z, k g /$ dozen $)$ & 0,454 & 0,416 & 0,397 & 0,388 & 0,357 & 7,969 \\
\hline
\end{tabular}

1 Efeito linear (Linear effect) $(\mathrm{P}<0,01): \hat{\mathrm{Y}}=63,31020-0,011721 \mathrm{X} ; \mathrm{R}^{2}=0,90$.

2 Efeito quadrático (quadratic effect) $(\mathrm{P}<0,052): \hat{\mathrm{Y}}=-1007,19+0,758615 \mathrm{X}-0,000130719 \mathrm{X}^{2} ; \mathrm{R}^{2}=0,88$.

2 Efeito linear (Linear effect) $(P<0,01): \hat{Y}=17,966958-0,001962 X ; R^{2}=0,95$

${ }^{3}$ Efeito linear (Linear effect) $(P<0,01): \hat{Y}=5,426954-0,000952 X ; R^{2}=0,85$.

${ }^{4}$ Efeito linear (Linear effect) $(P<0,01): \hat{Y}=1,03174-0,000221 X ; R^{2}=0,95$. 
Tabela 3 - Valores médios de eficiência energética por dúzia (EEDZ) e por massa de ovos (EEMO), ganho de peso (GP), pesos de gema (PG), de albúmem (PA) e de casca (PC) e concentração de colesterol na gema (COL) do ovo de codornas européias, segundo os níveis de EM utilizados na ração

Table 3 - $\quad$ Average values of energy efficiency per egg dozen (EEDZ), energy efficiency per egg mass (EEEM), weight gain (WG), weights of yolk (YW), albumen (AW) and shell (SW) and yolk cholesterol concentration (COL) of European quails according to the dietary ME levels

\begin{tabular}{|c|c|c|c|c|c|c|}
\hline \multirow{3}{*}{$\begin{array}{l}\text { Variável } \\
\text { Variable }\end{array}$} & \multirow{2}{*}{\multicolumn{5}{|c|}{$\begin{array}{c}\text { Nível de EM (kcal/kg) } \\
M E \text { level }\end{array}$}} & \multirow[t]{3}{*}{$\mathrm{CV}(\%)$} \\
\hline & & & & & & \\
\hline & 2.650 & 2.750 & 2.850 & 2.950 & 3.050 & \\
\hline EEDZ (kcal/dúzia) ${ }^{1}$ (EEDZ, kcal/dozen) & 1.203 & 1.143 & 1.138 & 1.146 & 1.090 & 8,059 \\
\hline EEMO (kcal/kg) (EEEM) & 7.888 & 7.477 & 13.738 & 13.642 & 12.879 & 17,419 \\
\hline $\mathrm{GP}(\mathrm{g})(W G)$ & 16,4 & 28,0 & 23,2 & 26,1 & 16,4 & 42,34 \\
\hline PG $(g)^{2}(Y W)$ & 3,94 & 3,92 & 3,85 & 3,83 & 3,70 & 6,077 \\
\hline PA $(\mathrm{g})^{3}(A W)$ & 7,71 & 7,69 & 7,40 & 7,30 & 7,26 & 4,431 \\
\hline $\mathrm{PC}(\mathrm{g})(S W)$ & 1,06 & 1,06 & 1,05 & 1,07 & 1,01 & 4,094 \\
\hline $\mathrm{COL}(\mathrm{mg} / \mathrm{g})(\mathrm{COL})$ & 13,611 & 13,855 & 13,738 & 13,642 & 12,879 & 17,419 \\
\hline
\end{tabular}

${ }^{1}$ Efeito linear (Linear effect) $(\mathrm{P}<0,01): \hat{\mathrm{Y}}=1781,049-0,223504 \mathrm{X} ; \mathrm{R}^{2}=0,77$.

2 Efeito linear (Linear effect) $(P<0,01): \hat{Y}=5,209375-0,000429 X ; R^{2}=0,72$.

3 Efeito linear (Linear effect) $(P<0,01): \hat{Y}=11,182973-0,001302 X ; R^{2}=0,91$.

87,1 kcal de EM/ave, dependendo do nível de energia da ração. Oliveira (2003), no entanto, encontrou para codornas européias consumo de $100,5 \mathrm{kcal}$, em ração contendo $2.800 \mathrm{kcal}$ de EM/kg. Estes dados indicam que as codornas européias, por seu maior peso corporal e metabólico, necessitam de maior aporte energético diário para manutenção de suas atividade vitais.

A produção total de ovos/ave/dia sofreu efeito quadrático $(\mathrm{P}<0,052)$ dos níveis de energia, observando-se maior produção nas aves alimentadas com ração contendo 2.900kcaldeEM/kg $\left(\hat{\mathrm{Y}}=-1007,19+0,758615 \mathrm{X}-0,000130719 \mathrm{X}^{2}\right.$; $\mathrm{R}^{2}=0,88$ ). Esses dados divergem dos obtidos por Yamane et al. (1980), Murakami et al. (1993) e Cordeiro et al. (2003), que verificaram redução na porcentagem de postura com o aumento do nível de energia da ração. Diferem também daqueles registrados por Freitas et al. (2005), Belo et al. (2000) e Pinto et al. (2002), que não notaram efeito dos níveis de energia sobre a produção de ovos. Estes autores também mantiveram o nível fixo de proteína na ração, independentemente dos níveis de energia avaliados.

De modo geral, a produção de ovos manteve-se bem elevada em todos os tratamentos, variando de 91 a $94 \%$, com exceção do tratamento no qual as aves foram alimentadas com ração contendo $2.650 \mathrm{kcal}$ de EM $/ \mathrm{kg}(84,6 \%)$. A produção de ovos obtida com a ração contendo $2.850 \mathrm{kcal}$ de $\mathrm{EM} / \mathrm{kg}$ foi 9,$2 ; 3,0 ; 2,9 \mathrm{e} 3,3 \%$ superior àquela registrada nos tratamentos com 2.650, 2.750, 2.950 e $3.050 \mathrm{kcal}$ de $\mathrm{EM} / \mathrm{kg}$, respectivamente. Ressalta-se também que a produção de ovos por esta subespécie não foi inferior à obtida com codornas japonesas na fase inicial de postura (Pinto et al., 2002; Pereira, 2004; Freitas et al., 2005), o que comprova que estas subespécies são igualmente eficientes quanto ao número de ovos produzidos nessa fase.
Oliveira (2003) registrou em codornas européias produção média semanal de 6,3 ovos/ave durante as primeiras 41 semanas de produção, o que corresponde a $90 \%$ de produção de ovos/ave/dia, indicando também excelente desempenho desta subespécie.

Diferentemente do observado para a produção de ovos/ ave/dia, os níveis de energia não afetaram $(\mathrm{P}>0,05)$ a produção de ovos comercializáveis, que foi elevada em praticamente todos os tratamentos, não ocorrendo perdas significativas em nenhum dos tratamentos.

Verificou-se redução $(\mathrm{P}<0,01)$ de $0,00196 \mathrm{~g}$ no peso médio dos ovos para cada aumento de $1 \mathrm{kcal}$ de EM/kg de ração ( $\hat{Y}=17,966958-0,001962 X ; R^{2}=0,95$ ), o que está de acordo com o observado por Freitas et al. (2005), Belo et al. (2000) e Pinto et al. (2002), que também notaram redução do peso do ovo com o aumento do nível energético da ração. A variação no peso foi de $0,72 \mathrm{~g}$ entre os pesos obtidos para o menor e o maior nível de energia avaliado, provavelmente em virtude do menor consumo de ração e, conseqüentemente, de todos os nutrientes, principalmente proteína e metionina, que influenciaram o peso, mas não a produção de ovos. Sabe-se que, em condições de deficiência de proteína na ração, o tamanho dos ovos tende a reduzir, enquanto a produção é mantida com objetivo de perpetuar a espécie. As aves alimentadas com ração contendo $2.650 \mathrm{kcal}$ de $\mathrm{EM} / \mathrm{kg}$ de ração mantiveram consumo diário de $155 \mathrm{mg}$ de metionina, enquanto aquelas que receberam ração contendo $3.050 \mathrm{kcal}$ de EM/kg consumiram $131 \mathrm{mg}$ de metionina, sendo este consumo $15,5 \%$ inferior.

Com base na composição do ovo e em pesquisas, Begin \& Insko Jr. (1972) relataram que codornas japonesas em postura alimentadas com rações à base de milho e farelo de soja requerem $20 \%$ de PB quando a ração contém $2.750 \mathrm{kcal}$ 
de EM/kg e $22 \%$ quando o teor de energia é de $2.890 \mathrm{kcal}$ de $\mathrm{EM} / \mathrm{kg}$. Os autores recomendaram para obtenção de máxima produção de ovos consumo diário de pelo menos $4,71 \mathrm{~g} \mathrm{de}$ proteína/ave para manutenção da taxa de postura em torno de $80 \%$. Yamane et al. (1980), Pinto et al. (2002) e Freitas et al. (2005) recomendaram para codornas japonesas consumo diário de 4,9; 6,0 e 4,4 g de proteína/ave, respectivamente, para ótimos índices de produção. Neste estudo, as aves alimentadas com a ração contendo $3.050 \mathrm{kcal}$ de EM/kg apresentaram consumo diário de proteína de $5,4 \mathrm{~g}$, enquanto aquelas alimentadas com ração contendo 2.650 e $2.750 \mathrm{kcal} / \mathrm{kg}$ tiveram consumo diário de 6,4 e $6,2 \mathrm{~g}$ de proteína/ave, respectivamente. O consumo diário de 5,4 $\mathrm{g}$ de PB nas aves alimentadas com ração contendo $3.050 \mathrm{kcal}$ de EM/kg foi $12,9 \mathrm{e} 15,6 \%$ inferior ao obtido com os níveis de 2.750 de $2.650 \mathrm{kcal} / \mathrm{kg}$, respectivamente, resultando em menor peso do ovo. Pode-se inferir, portanto, que o consumo diário de 6,2 g de proteína/ave parece ser apropriado para a codorna européia. Este valor é próximo ao recomendado por Pinto et al. (2002) para codornas japonesas $(6,0 \mathrm{~g})$.

De acordo com Perly (1979), Murakami \& Furlan (2002) e Pinto et al. (2002), o peso do ovo é altamente dependente da ingestão diária de proteína em poedeiras, podendo ser utilizado como referência para garantir suas exigências em aminoácidos.

O peso dos ovos destas codornas foi mais alto que os observados por Freitas et al. (2005) na subespécie japonesa, de 10,3 a 10,0 g para o maior e o menor nível de energia, respectivamente, obtidos com os níveis de 2.585 a 2.885 $\mathrm{kcal}$ de EM/kg. Pinto et al. (2002) encontraram valores de 10,68 a $10,85 \mathrm{~g}$ ao avaliarem níveis de 3.050 a 2.850 kcal de EM/kg de ração. No entanto, trabalhando com quatro grupos genéticos de codornas européias alimentadas com ração contendo $2.900 \mathrm{kcal}$ de EM/kg e $20 \%$ de PB, Móri et al. (2005b) encontraram para o peso do ovo variação de 12,81 a 13,45 g. Portanto, desconsiderando a conversão alimentar, o peso do ovo pode ser considerado outra vantagem na criação de codornas européias, principalmente quando se pretende processá-los e vendê-los descascados, por peso, agregando valor ao produto, quando o interesse é a criação e exploração de codornas européias (carne e ovos).

Apesar da redução do peso do ovo e da melhora da produção de ovos, a massa de ovos não foi significativamente $(\mathrm{P}>0,05)$ afetada pela elevação dos níveis energéticos da ração. A redução foi de 10,76 e de 10,97 g para o menor e o maior nível de EM, respectivamente, e correspondeu a um pequeno aumento, não-significativo, de 1,95\%. Resultados contraditórios, com redução linear de 7,7\% na massa diária de ovo, foram observados por Freitas et al. (2005), entre o menor e o maior nível de energia avaliado, de 2.585 e $2.885 \mathrm{kcal}$ de EM/kg de ração, respectivamente.

Em decorrência da redução do consumo de ração, de $15,4 \%$ entre o menor e o maior nível de energia da dieta, e da ausência de diferenças significativas para a massa dos ovos, houve melhoras significativas $(\mathrm{P}<0,01)$, de 0,00022 pontos na conversão alimentar por dúzia de ovos ( $\hat{Y}=1,03174-0,000221 X ; R^{2}=0,95$ ) e de 0,00095 pontos na conversão alimentar por massa de ovos ( $\hat{Y}=5,426954$ $\left.0,000952 X ; R^{2}=0,85\right)$, para cada aumento de $1 \mathrm{kcal}$ de $\mathrm{EM} / \mathrm{kg}$ de ração.

Estes resultados corroboram os encontrados por Pinto et al. (2002), que verificaram que os níveis entre 2.950 e $3.050 \mathrm{kcal}$ de $\mathrm{EM} / \mathrm{kg}$ permitiram os melhores valores para a conversão alimentar de codornas japonesas. Estão também parcialmente de acordo com os de Murakami et al. (1993), que registraram melhora da conversão alimentar por dúzia de ovos, mas não por massa de ovos, com o aumento de 2.500 para $3.000 \mathrm{kcal}$ de EM/kg nos níveis de energia das rações. Freitas et al. (2005), no entanto, não encontraram diferenças significativas para a conversão alimentar por massa de ovo ao avaliarem rações formuladas com 2.585 a $2.885 \mathrm{kcal} \mathrm{de} \mathrm{EM} / \mathrm{kg}$.

Ressalta-se que uma das desvantagens na criação da codorna européia, em comparação às codornas japonesas, é seu maior peso (100-120 $\mathrm{g}$ a mais) e mais alto consumo de ração (8-12 g a mais), que contribuem para piora na conversão alimentar. Todavia, em estudo com codornas européias, Oliveira (2003) encontrou valores de $0,47 \mathrm{~kg} /$ dúzia de ovos e de 3,12 para a conversão alimentar por massa de ovos. Neste trabalho, a conversão alimentar por massa de ovos variou de 2,98 a 2,53 entre os níveis de energia avaliados, enquanto, nos trabalhos de Freitas et al. (2005), com níveis de energia próximos ao deste trabalho, a conversão foi de 3,19 a 3,27.

Verificou-se que apenas a eficiência energética para produção de uma dúzia de ovos, em comparação à eficiência para produção de $1 \mathrm{~kg}$ de ovos, foi significativamente influenciada $(\mathrm{P}<0,01)$ pelos níveis de EM. Houve redução de $0,2235 \mathrm{kcal}$ na eficiência energética das aves para produção de uma dúzia de ovos a cada aumento de $1 \mathrm{kcal}$ de $\mathrm{EM} / \mathrm{kg}$ de ração ( $\left.\hat{Y}=1781,049-0,223504 \mathrm{X} ; \mathrm{R}^{2}=0,77\right)$. Esses dados revelam que foi mais eficiente, energeticamente, produzir uma dúzia de ovos com o fornecimento de $3.050 \mathrm{kcal}$ de EM/kg de ração. Entretanto, Belo (1997) não encontraram efeito dos níveis de energia da ração sobre a eficiência energética para produção de uma dúzia ou de $1 \mathrm{~kg}$ de ovos.

Os grupos de aves alimentadas com dietas formuladas com 2.650 a $3.050 \mathrm{kcal}$ de EM/kg não diferiram significativa- 
mente $(\mathrm{P}>0,05)$ quanto ao ganho e à perda de peso. Esse resultado corrobora os obtidos por Pinto et al. (2002), que também não notaram efeito do nível de energia da ração sobre o ganho de peso das aves no período experimental. Com base nos resultados, pode-se inferir que todas as rações foram eficientes para manutenção do peso, o que poderia afetar a produtividade. As dietas contendo o menor e o maior nível de energia proporcionaram os menores ganhos de peso em valor absoluto. No entanto, o baixo ganho de peso das aves alimentadas com a ração contendo o maior nível de energia (3.050 kcal de EM/ $/ \mathrm{kg}$ ) foi suficiente para manter elevada produção, quando comparado ao mesmo ganho obtido com a dieta contendo o menor nível de energia $(2.650 \mathrm{kcal}$ de $\mathrm{EM} / \mathrm{kg})$.

Observou-se redução significativa $(\mathrm{P}<0,01)$ de $0,00043 \mathrm{~g}$ no peso de gema $(\hat{\mathrm{Y}}=5,209375-0,000429 \mathrm{X}$; $\left.\mathrm{R}^{2}=0,72\right)$ e de $0,00130 \mathrm{~g}$ no peso de albúmem ( $\left.\hat{Y}=11,182973-0,001302 X ; R^{2}=0,91\right)$ com o aumento do nível de energia da ração. Entretanto, o mesmo não foi verificado para o peso da casca do ovo. A redução no peso da gema e no peso de albúmem foi acompanhada pela redução no peso do ovo com o aumento do nível de EM da ração, provavelmente em virtude da menor quantidade de nutrientes necessários à formação do ovo. Fonseca (1992), em experimento com galinhas poedeiras, forneceu ração contendo níveis mais baixos de energia e obteve ovos com maior espessura de casca.

O teor de colesterol na gema do ovo não foi influenciado $(\mathrm{P}>0,05)$ pelo nível de energia da ração, o que confirma os achados de Quirino et al. (2004), que também não notaram aumento no teor de colesterol na gema dos ovos de codornas japonesas alimentadas com ração contendo os mesmos níveis de energia avaliados neste trabalho.

\section{Conclusões}

Rações para codornas européias em fase inicial de postura (56 aos 168 dias) devem conter $3.050 \mathrm{kcal} \mathrm{de} \mathrm{EM/kg}$ (correspondente a um consumo de $82,4 \mathrm{kcal}$ de EM/ave/dia ou a 7,5 kcal de EM/g de ovo) para obtenção de melhor conversão alimentar por massa e por dúzia de ovos ou $2.900 \mathrm{kcal}$ de $\mathrm{EM} / \mathrm{kg}$ (correspondente a um consumo de $87 \mathrm{kcal}$ de EM/ave/dia ou a 7,5 kcal de EM/g de ovo) para melhor produção de ovos.

\section{Literatura Citada}

ALMEIDA, M.I.M. Efeito de linhagem e de nível protéico sobre o desempenho e características de carcaça de codornas (Coturnix sp) criadas para corte. Botucatu: Universidade Estadual Paulista, 2001. 96p. Tese (Doutorado em Melhoramento Genético) - Universidade Estadual Paulista, 2001.
ALBINO, L.F.T.; BARRETO, S.L.T. Criação de codornas para produção de ovos e carnes. Viçosa, MG: Aprenda Fácil, 2003. $289 \mathrm{p}$.

BELO, M.T.S. Níveis de energia metabolizável e de metionina em rações de codornas japonesas (Coturnix coturnix japonica) na fase inicial de postura. Lavras: Universidade Federal de Lavras, 1997. 60p. Dissertação (Mestrado em Zootecnia) - Universidade Federal de Lavras, 1997.

BELO, M.T.S.; COTTA, J.T.B.; OLIVEIRA, A.I.G. et al. Níveis de energia metabolizável em rações de codornas japonesas (Coturnix coturnix japonica) na fase inicial de postura. Ciências Agrotécnicas, v.24, n.3, p.782-794, 2000.

BEGIN, J.J. A comparison of the ability of the Japanese quail and light breed chicken to metabolizable and utilize energy. Poultry Science, v.47, n.4, p.1278-1281, 1968.

BEGIN, J.J.; INSKO JR., W.M. The Effects of dietary protein level on the reproductive performance of coturnix breeder hens. Poultry Science, v.51, n.5, p.1662-1668, 1972.

BRAGAGNOLO, N.R.; AMAYA, D.B. Comparison of the cholesterol content of Brazilian chicken and quail eggs. Journal of Food Composition and Analysis, v.16, p.147-153, 2003.

CORDEIRO, M.D.; SOARES, R.T.R.N.; AVILA, R.P. et al. Níveis de energia metabolizável para codornas japonesas (Coturnix coturnix japonica) na fase inicial de postura. In: REUNIÃO ANUAL DA SOCIEDADE BRASILEIRA DE ZOOTECNIA, 40., 2003, Santa Maria. Anais... Santa Maria: Sociedade Brasileira de Zootecnia, 2003. (CD-ROM).

FREITAS, A.C.; FUENTES, M.F.F.; FREITAS, E.R. et al. Efeito de níveis de proteína bruta e de energia metabolizável na dieta sobre o desempenho de codornas de postura. Revista Brasileira de Zootecnia, v.34, n.3, p.838-846, 2005.

FONSECA, R.A. Níveis de energia em duas linhagens de poedeiras leves, na fase inicial de postura. Lavras: Universidade Federal de Lavras, 1992. 123p. Dissertação (Mestrado em Zootecnia) - Universidade Federal de Lavras, 1992.

MÓRI, C.; GARCIA, E.A.; PAVAN, A.C. et al. Desempenho e rendimento de carcaça de quatro grupos genéticos de codornas para produção de carne. Revista Brasileira de Zootecnia, v.34, n.3, p.870-876, 2005a.

MÓRI, C.; GARCIA, E.A.; PAVAN, A.C. et al. Desempenho e qualidade dos ovos de codornas de quatro grupos genéticos. Revista Brasileira de Zootecnia, v.34, n.3, p.864-869, 2005 b.

MURAKAMI, A.E.; FURLAN, A.C. Pesquisa na nutrição e alimentação de codornas em postura no Brasil. In: SIMPÓSIO INTERNACIONAL DE COTURNICULTURA, 1., 2002, Lavras. Anais... Lavras: Universidade Federal de Lavras, 2002. p.113-120.

MURAKAMI, A.E.; MORAES, V.M.B.; ARIKI, J. Níveis de proteína e energia em dietas de codornas japonesas (Coturnix coturnix japonica) em postura. Revista Brasileira de Zootecnia, v.22, n.4, p.541-551, 1993.

NATIONAL RESEARCH COUNCIL - NRC. Nutrient requirements of poultry. Washington, D.C.: 1994. p.44-45.

NETO, G.J. Aspectos nutricionais que afetam as características especificas do ovo de incubação. In: CONFERÊNCIA APINCO DE CIÊNCIA E TECNOLOGIA AVÍCOLAS, 1999, Campinas. Anais... Campinas: Fundação Apinco de Ciência e Tecnologia Avícolas, 1999. p.145-164.

OLIVEIRA, L.Q.M. Parâmetros produtivos e níveis nutricionais de cálcio para codorna européia na fase de postura. Brasília: Universidade de Brasília, 2003. 55p. Dissertação (Mestrado em Ciências Agrárias) - Universidade de Brasília, 2003.

PEREIRA, C.A. Exigência nutricional de cálcio para codornas japonesas durante o pico de postura. Viçosa, MG: Universidade Federal de Viçosa, 2004. 60p. Dissertação (Mestrado em Zootecnia) - Universidade Federal de Viçosa, 2004.

PERLY, L. Correlação entre índice morfológico, peso do ovo e peso vivo ao final da fase de crescimento em codornas doméstica 
(Coturnix coturnix japonica). Revista do Setor de Ciências Agrárias, v.1, n.1, p.41-53, 1979.

PINTO, R.; FERREIRA, A.S.; ALBINO, L.F.T. et al. Níveis de proteína e energia para codornas japonesas em postura. Revista Brasileira de Zootecnia, v.31, n.4, p.1761-1770, 2002.

PINTO, R.; DONZELE, J.L.; FERREIRA, A.S. et al. Exigência de metionina mais cistina para codornas japonesas em postura. Revista Brasileira de Zootecnia, v.32, n.5, p.1166-1173, $2003 \mathrm{a}$.

PINTO, R.; FERREIRA, A.S.; DONZELE, J.L. et al. Exigência de lisina para codornas japonesas em postura. Revista Brasileira de Zootecnia, v.32, n.5, p.1182-1189, 2003b.

QUIRINO, B.J.S.; BARRETO, S.L.T.; UMIGI, R.T. et al. Efeitos de níveis de energia para codornas japonesas durante o pico de postura. In: CONGRESSO BRASILEIRO DE COTURNICULTURA, 1., 2004, Lavras. Anais... Lavras: Universidade Federal de Lavras, 2004. p.207.
ROSTAGNO, H.S.; ALBINO, L.F.T.; DONZELE, J.L. et al. Composição de alimentos e exigências nutricionais de aves e suínos (Tabelas brasileiras). Viçosa, MG. Universidade Federal de Viçosa, 2000. 141p.

UNIVERSIDADE FEDERAL DE VIÇOSA - UFV. SAEG - Sistema de análises estatísticas e genéticas. Versão 9,0. Viçosa, MG: Fundação Arthur Bernardes, 2004. (CD-ROM).

YAMANE, T.; ONO, K.; TANAKA, T. Energy requirement of laying Japanese quail. British Poultry Science, v.21, n.6, p.451-455, 1980. 